Dikirim: 7 Juli 2017

Diterbitkan: 1 Februari 2018

\section{Usia menarche sebagai faktor risiko kejadian preeklamsia dan eklamsia}

\section{Age of menarche as a risk factor for preeclampsia and eclampsia}

Astrid Kizy Primadani ${ }^{1}$, Elisabeth S Herini ${ }^{2}$, Djaswadi Dasuki ${ }^{2}$

\section{Abstract}

Purpose: The purpose of this study was to determine the effect of menarche age on the incidence of preeclampsia and eclampsia. Method: The observational study with case control design was conducted involving 90 pregnant and postpartum women. Bivariable analysis used T-test and McNemar test, while multivariable analysis using conditional logistic regression. Results: The average age of menarche in the preeclampsia group was one year younger than the non-preeclampsia group. Any increase in one year of age of menarche lower the risk of preeclampsia and eclampsia by $78 \%$. Risk factors for preeclampsia are increased in pregnant women at age> 35 years and have body mass index before pregnancy $>25 \mathrm{~kg} / \mathrm{m}^{2}$. Conclusion: There was a significant relationship between age of menarche and the incidence of preeclampsia and eclampsia. Body mass index before pregnancy is a confounding factor of the association between age of menarche and the incidence of preeclampsia and eclampsia.

Keywords: preeclampsia; eclampsia; age of menarche; case-control; body mass index

\footnotetext{
${ }^{1}$ Departemen Biostatistik, Epidemiologi, dan Kesehatan Populasi, Fakultas Kedokteran, Universitas Gadjah Mada (Email: astrid_ao@yahoo.com.id)

${ }^{2}$ Departemen Ilmu Kesehatan Anak, Fakultas Kedokteran, Universitas Gadjah Mada
} 


\section{PENDAHULUAN}

WHO melaporkan $16 \%$ penyebab kematian ibu di dunia disebabkan oleh hipertensi. Di Amerika Serikat sejak 1998 sampai 2005, 12,3\% dari 4693 ibu hamil meninggal karena preeklamsia dan eklamsia (1). Sementara itu angka kematian ibu di Indonesia masih tinggi sebesar 359 per 100.000 kelahiran hidup. Preeklamsia menduduki peringkat kedua sebagai penyebab kematian ibu (2).

Penyebab preeklamsia masih belum diketahui pasti. Preeklamsia disebut sebagai diseases of theory. Investigasi dan identifikasi merupakan faktor terpenting dalam menentukan kebijakan dan tujuan klinis, termasuk prioritas intervensi, alokasi sumber daya, identifikasi ibu hamil risiko tinggi untuk pengamatan dan perawatan lebih intensif (3). Preeklamsia adalah penyakit tidak memiliki natural history yang jelas. Hubungan preeklamsia, proteinuria, oedema atau ketidaknormalan biokemikal sebagai indikator keparahan preeklamsia tidak jelas. Karena itu wanita dengan preeklamsia berisiko tinggi memiliki penyakit kehamilan yang berat.

Faktor risiko penyebab preeklamsia adalah usia, nullipara, kehamilan pasangan baru, jarak kehamilan, riwayat preeklamsia, riwayat preeklamsia pada keluarga, kehamilan multifetus, donor oosit atau sperma, diabetes mellitus tipe I, penyakit ginjal, sindrom antifosfolipid, hipertensi kronik, obesitas sebelum kehamilan, kondisi sosio-ekonomi, dan frekuensi ANC. Faktor lain yang diduga berhubungan dengan preeklamsia adalah usia menarche. Kelebihan timbunan lemak tubuh berpengaruh terhadap asal mula hubungan usia menarche dengan preeklamia (4).

Usia menarche yang terlalu dini adalah faktor risiko gestational hypertension. Hasil pada studi di Swedish Medical Center Seattle menunjukkan hubungan terbalik antara usia menarche dan peningkatan risiko preeklamsia. Primigravida usia 12-14 tahun memiliki insiden maksimum terhadap kehamilan yang diinduksi oleh hipertensi (5).

Usia menarche yang menjadi penyebab kejadian preeklamsia belum diketahui. Penelitian menunjukkan bahwa usia menarche berpengaruh pada kejadian preeklamsia walaupun masih ada beberapa penelitian yang tidak signifikan, sehingga perlu dilakukan penelitian lebih lanjut untuk mengetahui pengaruh usia menarche terhadap kejadian preeklamsia $(6,7)$.

\section{METODE}

Penelitian observasional analitik ini menggunakan rancangan case control melibatkan 90 wanita. Penelitian dilaksanakan di klinik kandungan, ruang kamar bersalin dan ruang nifas patologi Rumah Sakit PKU Muhammadiyah Yogyakarta dan rumah sakit Panembahan Senopati. Variabel bebas adalah usia menarche, sedangkan variabel terikat adalah preeklamsia dan eklamsia. Variabel luar adalah usia ibu, pendidikan, pekerjaan, paritas, dan indeks massa tubuh (IMT). Subyek penelitian adalah seluruh ibu hamil dan ibu postpartum yang diambil dengan cara pemadanan sesuai dengan kriteria inklusi: usia kehamilan $>20$ minggu, dan kehamilan tunggal. Teknik pengambilan sampel menggunakan metode consecutive sampling. Instrumen pengumpulan data untuk mengukur variabel-variabel dalam penelitian ini diadopsi dari SKRT dan penelitian sebelumnya (8).

\section{HASIL}

Tabel 1 menunjukkan usia menarche responden pada kelompok kasus satu tahun lebih muda dibandingkan dengan kelompok kontrol.

Tabel 1. Rerata usia menarche dari kelompok kasus dan kelompok kontrol

\begin{tabular}{lllll}
\hline & Obs & Rerata & Min & Max \\
\hline Kasus & 45 & 12,6 & 9 & 17 \\
Kontrol & 45 & 13,4 & 11 & 17 \\
\hline
\end{tabular}

Tabel 2 menunjukkan proporsi terbesar pendapatan keluarga pada kedua kelompok kasus dan kontrol adalah kurang dari 1 juta rupiah dan proporsi terkecil pada kelompok kasus maupun kontrol adalah > 3 juta rupiah. Variabel usia dengan jumlah proporsi terbesar pada kelompok kasus dan kontrol yaitu usia 20-34 tahun sebanyak 58\% dan 76\%. Proporsi terbesar variabel pendidikan pada kelompok kasus maupun kontrol adalah pendidikan rendah sebanyak 80\% responden dan $71 \%$ responden. Proporsi terbesar baik pada kelompok kasus maupun kontrol sebanyak 80\% dan $69 \%$ responden terdapat pada kategori pekerjaan informal. Berdasarkan jumlah paritas, baik kasus maupun kontrol memiliki proporsi terbesar pada kategori wanita yang pernah melahirkan 2-4 kali sebanyak 60\% kelompok kasus dan 51\% kelompok kontrol. kelompok kasus lebih banyak memiliki IMT> $25 \mathrm{~kg} / \mathrm{m} 2$ (64\%) 
Tabel 2. Ciri-ciri responden berdasarkan kondisi preeklampsia dan non-preekmplasi

\begin{tabular}{lcc}
\hline \multicolumn{1}{c}{ Variabel } & $\begin{array}{c}\text { Preeklamsia } \\
\text { (\%) } \mathbf{n = 4 5}\end{array}$ & $\begin{array}{c}\text { Non- } \\
\text { preeklamsia } \\
\text { (\%) } \mathbf{n}=\mathbf{4 5}\end{array}$ \\
\hline $\begin{array}{l}\text { Pendapatan } \\
\text { <1 juta }\end{array}$ & 40 & \\
2-3juta & & 40 \\
$>3$ juta & 33 & 33 \\
Usia ibu (tahun) & 27 & 27 \\
$<20$ atau $\geq 35$ & 58 & 76 \\
20-34 & 42 & 24 \\
Pendidikan & & \\
Tinggi & 20 & 29 \\
Rendah & 80 & 71 \\
Pekerjaan & & \\
Formal & 20 & 31 \\
Informal & 80 & 69 \\
Paritas & & \\
0-1 kali & 40 & 49 \\
$\geq 2 \mathrm{kali}$ & 60 & 51 \\
IMT & & 73 \\
$<25 \mathrm{~kg} / \mathrm{m}^{2}$ & 36 & 27 \\
$\geq 25 \mathrm{~kg} / \mathrm{m}^{2}$ & 64 & \\
\hline
\end{tabular}

Tabel 3 menunjukkan setiap kenaikan satu tahun usia menarche menurunkan risiko preeklamsia atau eklamsia sebesar $78 \%$ setelah mempertimbangkan usia ibu, pendidikan, pekerjaan, dan indeks massa tubuh.

Tabel 3. Crude odds ratio preeklamsia menurut usia menarche, usia ibu, pendidikan, pekerjaan, paritas, dan IMT dengan kejadian preeklamsia/eklamsia.

\begin{tabular}{|c|c|c|c|c|}
\hline Variabel & $\frac{\text { Kasus }}{n}$ & Kontrol & $1 \begin{array}{c}\text { Crude OR } \\
(95 \% \mathrm{CI})\end{array}$ & $\begin{array}{l}\text { Adjusted OR } \\
(95 \% \mathrm{CI})\end{array}$ \\
\hline Usia menarche & & & $\begin{array}{c}0,75 \\
(0,57-0,98)\end{array}$ & $\begin{array}{c}0,22 \\
(0,66-0,71)\end{array}$ \\
\hline Usia ibu (tahun) & & & & \\
\hline$<20$ ata & 19 & 11 & $\begin{array}{c}2,6 \\
(0,87-9,31)\end{array}$ & $\begin{array}{c}71 \\
(1,55-3226,1)\end{array}$ \\
\hline $\begin{array}{l}20-34 \\
\text { Pendidikan }\end{array}$ & 26 & 34 & 1 & 1 \\
\hline Tinggi & 9 & 13 & $\begin{array}{l}1 \\
2\end{array}$ & $\begin{array}{l}1 \\
3,5\end{array}$ \\
\hline $\begin{array}{l}\text { Rendah } \\
\text { Pekerjaan }\end{array}$ & 36 & 32 & $(0,54-9,07)$ & $(0,50-24,1)$ \\
\hline Forma & 9 & 14 & $\begin{array}{c}0,44 \\
(0,10-1,59)\end{array}$ & $\begin{array}{c}0,01 \\
(0,00-0,42)\end{array}$ \\
\hline $\begin{array}{l}\text { Informal } \\
\text { Paritas }\end{array}$ & 36 & 31 & 1 & 1 \\
\hline Primipara & 18 & 22 & $\begin{array}{c}1,2 \\
(0,44-3,64)\end{array}$ & \\
\hline $\begin{array}{l}\text { Multipara } \\
\text { IMT }\end{array}$ & 27 & 23 & 1 & \\
\hline$<25 \mathrm{~kg} / \mathrm{m}^{2}$ & 16 & 33 & $\begin{array}{c}1 \\
6,7\end{array}$ & $\begin{array}{c}1 \\
6.55 \\
(4.7-911055)\end{array}$ \\
\hline$>25 \mathrm{Kg} / \mathrm{I}$ & & & & $(4,1-91105,5)$ \\
\hline
\end{tabular}

Usia menarche berkaitan dengan preeklamsia, sedangkan usia ibu, pendidikan, paritas dan indeks massa tubuh berhubungan secara praktis tetapi tidak secara statistik. Setelah mengontrol faktor lain, usia menarche, pendidikan, pekerjaan, dan indeks massa tubuh tidak ada perubahan signifikansi, sedangkan usia ibu berhubungan dengan hipertensi setelah mengontrol faktor lain.

\section{BAHASAN}

Penelitian menemukan setiap kenaikan satu tahun usia menarche dapat menurunkan risiko pre- eklamsia sebesar 78\%. Kondisi ini disebabkan karena wanita dengan usia menarche dini mengalami ke- matangan organ tubuh lebih awal dan risiko untuk mengalami obesitas lebih besar bila dibandingkan dengan wanita yang memiliki usia menarche normal karena obesitas merupakan salah satu faktor utama penyebab preeklamsia. Menarche kurang dari 12 tahun meningkatkan risiko preeklamsia (6). Penelitian menunjukkan bahwa rata-rata ibu primigravida dengan rata-rata usia menarche 12 sampai 14 tahun lebih berisiko menga- lami hipertensi gestasional (5).

Penelitian menemukan hubungan usia menarche dengan tekanan darah sistolik pada masa pubertas yang terlambat. Studi ini menjelaskan kemungkinan hubungan usia menarche dini dengan jaringan lemak yang lebih besar. Penelitian ini menjelaskan hubungan usia menarche dini dengan tekanan darah sistolik yang tinggi sebagian dimediasi oleh indeks massa tubuh. Hubungan ini bisa terjadi karena berbagai alasan, pertama hubungan antara usia menarche dengan penyakit jantung menyebabkan obesitas muncul untuk meningkatkan pubertas awal. Arsitektur genetik mendorong usia menarche dan obesitas tetapi tidak dengan tekanan darah. Genome wide association studies (GWAS) menunjukkan macam-macam genetik, termasuk ADCY3-PDMC dan PXMP3. Kedua genetik itu mempengaruhi usia menarche dan obesitas. Sebaliknya dasar genetik pubertas dan tekanan darah belum ditemukan walaupun GWAS hingga saat ini hanya menjelaskan sedikit saja persentase dari macam-macam tekanan darah (9).

Penelitian ini menemukan hubungan usia menarche dengan hipertensi secara praktis, sedangkan analisis multivariabel menunjukkan hubungan secara statistik maupun praktis. Hal ini sesuai dengan penelitian dimana ibu hamil dengan usia kurang dari 20 tahun berisiko tiga kali mengalami preeklamsia dibanding ibu hamil yang berusia di atas 20 tahun (10). Penelitian lain melaporkan bahwa remaja hamil lebih berisiko mengalami pregnancy-induced hypertension dan eklamsia (11). Sedangkan ibu hamil di atas 35 tahun berisiko hampir dua kali lebih tinggi mengalami preeklamsia dibanding ibu yang berusia di bawah 35 tahun (12). Faktor yang mempengaruhi preeklamsia sebelum usia 20 tahun adalah invasi trofoblastik awal dan bagaimana ibu bereaksi. Kegagalan invasi normal sel trofoblastik berdampak pada maladaptasi pada arteriol spiral yang terkait dengan sebab akibat pre- 
eklamsia. Peningkatan reaksi vena pada wanita di atas 30 tahun berperan sebagai faktor pendukung perkembangan preeklamsia (10).

Penelitian ini menunjukkan tidak ada hubungan signifikan antara pendidikan dengan kejadian preeklamsia dan eklamsia. Penelitian lain menyatakan wanita berpendidikan rendah berisiko lebih tinggi mengalami preeklamsia dibanding wanita berpendidikan tinggi. Penelitian menemukan wanita berpendidikan rendah memiliki risiko 1,7 kali untuk mengalami preeklamsia (13), namun pendidikan tidak memberikan penjelasan tepat tentang hubungan preeklamsia atau eklamsia dengan usia menarche (14). Penelitian ini menemukan pekerjaan mempengaruhi hubungan usia menarche dengan preeklamsia. Pekerjaan fisik seperti mendorong, menarik atau menaiki tangga, berdiri terlalu lama tanpa berjalan atau jongkok dapat meningkatkan risiko preeklamsia (5). Tekanan kerja, tidak ada waktu istirahat, dan jam kerja panjang meningkatkan preeklamsia. Sebagian besar penelitian menunjukkan jenis pekerjaan tidak memiliki kekuatan cukup untuk mendeteksi preeklamsia dan hipertensi gestasional (15).

Indeks massa tubuh berpengaruh besar pada hubungan usia menarche dengan preeklamsia. Penelitian ini menemukan ibu dengan obesitas sebelum kehamilan hampir 7 kali lebih besar mengalami preeklamsia. Obesitas meningkatkan risiko preeklamsia yang muncul pada awal atau akhir masa gestasi (7). Penelitian pada populasi Pittsburgh menunjukkan risiko preeklamsia meningkat 3 kali lebih besar pada wanita obese (15). Timbunan lemak dalam tubuh merupakan asal hubungan menarche dengan preeklamsia (8). Pada wanita overweight, usia menarche yang terlalu dini meningkatkan risiko preeklamsia.

\section{SIMPULAN}

Wanita yang memiliki usia menarche muda dan obesitas lebih besar kemungkinan mengalami preeklamsia.

\section{Abstrak}

Tujuan: Penelitian ini bertujuan mengetahui pengaruh usia menarche terhadap kejadian preeklamsia dan eklamsia. Metode: Penelitian observasional dengan rancangan case control dilakukan dengan melibatkan 90 ibu hamil dan postpartum. Analisis bivariabel menggunakan uji T untuk dan McNemar, sedangkan analisis multivariabel menggunakan conditional logistic regression. Hasil: Rata-rata usia menarche pada kelompok preeklamsia lebih muda satu tahun dibanding kelompok non-preeklamsia. Setiap kenaikan satu tahun usia menarche menurunkan risiko preeklamsia dan eklamsia sebesar 78\%. Faktor risiko preeklamsia meningkat pada ibu hamil di usia $>35$ tahun dan memiliki indeks massa tubuh sebelum hamil $>25 \mathrm{~kg} / \mathrm{m}^{2}$. Simpulan: Terdapat hubungan yang signifikan antara usia menarche dengan kejadian preeklamsia dan eklamsia. Indeks massa tubuh sebelum hamil adalah perancu hubungan usia menarche dengan kejadian preeklamsia dan eklamsia.

Kata kunci: preeklamsia; eklamsia; usia menarche; kasus kontrol; indeks massa tubuh

\section{PUSTAKA}

1. Cunningham, F, G., Corton, M, M., Leveno, K., and Bloom, S., William Obstetrics, 24eth ed, McGraw-Hill Education, USA; 2014.

2. SDKI. Survei Demografi dan Kesehatan Indonesia Tahun 2012; 2012.

3. Bilano, V.L., Ota, E., Ganchimeg, T., Mori, R. and Souza, J.P. Risk factors of pre-eclampsia/eclampsia and its adverse outcomes in low-and middle-income countries: a WHO secondary analysis, PLOS one 2014;9(3): e91198.

4. Ros, H.S., Lichtenstein, P., Ekbom, A. and Cnattingius, S. Tall or short? Twenty years after preeclampsia exposure in utero: comparisons of final height, body mass index, waist-to-hip ratio, and age at menarche among women, exposed and unexposed to preeclampsia during fetal life, Pediatric research 2001;49(6): 763-769.

5. Haelterman, E., Marcoux, S., Croteau, A. and Dramaix, M. Population-based study on occupational risk factors for preeclampsia and gestational hypertension. Scand J Work Environ Health 2007;33(4): 304-317.

6. Abetew, D.F., Enquobahrie, D.A., Dishi, M., Rudra, C.B., Miller, R.S. and Williams, M.A. Age at menarche, menstrual characteristics, and risk of preeclampsia, ISRN obstetrics and gynecology; 2011. Accessed: https://www.ncbi.nlm.nih.gov.

7. Lahiri, A., Bandyopadhyay, S., Adhya, S., Ghosh, S., Ray, S. and Haldar, S. A Study on Age at Menarche 
with its Relation to Pregnancy Induced Hypertension, JIAFM; 2014 36(4): 359-362.

8. Rudra, C.L. and Williams, M.A. BMI as a modifying factor in the relations between age at menarche, menstrual cycle characteristics, and risk of preeclampsia, Gynecological endocrinology 2005;21(4): 200-205.

9. Lai, T.C., Leung, G.M. and Schooling, C.M. Maternal Age of Menarche and Blood Pressure in Adolescence: Evidence from Hong Kong's "Children of 1997" Birth Cohort. PLoS One 2016;11(7): 0159855.

10. Kumari, N., Dash, K., Singh, R. Relationship between Maternal Age and Preeclampsia, IOSR-JDMS 2016;15(12): 55-57.

11. Duckitt K., Harington, D. Risk factors for preeclampsia at antenatal Booking: systematic review of controlled studies, BMJ 2005;330: 549-50.
12. Lamminpää, R., Vehviläinen-Julkunen, K., Gissler, M. and Heinonen, S. Preeclampsia complicated by advanced maternal age: a registry-based study on primiparous women in Finland 1997-2008. BMC pregnancy and childbirth 2012. Accessed: www.biomedcentral.com.

13. Optisari, C. dan Andayasari, L. Parity, education level and risk for (pre-) eclampsia in selected hospitals in Jakarta, Health Science Indones 2014;5(1): 35-39.

14. Manandhar, B.L., Chongstuvivatwong, V. and Geater, A. Antenatal care and severe pre-eclampsia in Kathmandu valley, JCMC 2014;3(4): 43-47.

15. .Chang, P.J., Chu, L.C., Hsieh, W.S., Chuang, Y.L., Lin, S.J. and Chen, P.C. Working hours and risk of gestational hypertension and pre-eclampsia. Occupational medicine 2010; 60(1): 66-71. 